Arteterapia. Papeles de arteterapia y educación para inclusión social ISSN-e 1988-8309

http://dx.doi.org/10.5209/ARTE.60129

\title{
Educación patrimonial orientada a la inclusión social para personas con TEA: los museos capacitantes
}

\author{
Laura Pablos ${ }^{1}$, Olaia Fontal Merillas ${ }^{2}$
}

Recibido: 4 de mayo de 2018/ Aceptado: 24 de julio de 2018

Resumen. Nos encontramos ante una sociedad plural y cambiante que demanda respuestas institucionales comprometidas y conjuntas, que tengan en cuenta a la persona como centro esencial de cualquiera de sus acciones. En este sentido, las acciones educativas desarrolladas en torno al patrimonio ofrecen el contexto adecuado para empoderar a los individuos, ya que les convierte en protagonistas de experiencias decididas por ellos mismos. De este modo la autodeterminación se convierte en la piedra angular de propuestas capacitantes desarrolladas en espacios que, por su propia naturaleza, llevan a cabo una importante función social, como son los museos.

En este contexto, tiene pleno sentido la generación de propuestas de trabajo de educación patrimonial que, pudiendo convertirse en inclusivas, faciliten el acceso de todo tipo de públicos a la institución democratizando de este modo el espacio a todos los colectivos, y en el caso concreto del trabajo que aquí presentamos, a las personas con trastorno del espectro autista (TEA).

Palabras clave: Museo; educación patrimonial; vínculo; capacitante; empoderar.

\section{[en] Heritage education oriented towards social inclusion of people with ASD: enabling museums}

\begin{abstract}
Today's plural changing society demands that our institutions provide committed and collaborative responses that consider people to be the centre of any action they may take. In this regard, educational activities carried out in the heritage environment provide a suitable setting to empower individuals, as they become the protagonists of experences that they have decided for themselves. Self-determination thus becomes the cornerstone of enabling proposals developed in museums which, by nature, play an important social role.

In this context, it is understandable to generate proposals for heritage education work that, being able to become inclusive, facilitate the access of all types of public to the institution, thereby democratizing the space to all groups, and in the case concrete of our proposal, to people with autism spectrum disorder (ASD).
\end{abstract}

Keywords: Museum; heritage education; link; enabling; empower.

Sumario: 1. Introducción; 2. La diversidad como eje vertebrador de propuestas empoderadoras; 3 . Los museos como contextos de inclusión social; 4. La educación patrimonial como disciplina inclusiva; 5. Entornos patrimoniales capacitantes; 6. Revisión de estudios en torno al TEA en museos; 7. La teoría puesta en práctica: ejemplos de referentes; 8. Conclusiones; 9. Referencias bibliográficas.

1 Doctoranda de la Universidad de Valladolid

E-mail: laurapablos@hotmail.com

2 Profesora Titular de Universidad de Valladolid. Directora del Observatorio de Educación Patrimonial en España (OEPE)

E-mail: olaia.fontal@uva.es 
Cómo citar: Pablos, L., Fontal Merillas, O. (2018). Educación patrimonial orientada a la inclusión social para personas con TEA: los museos capacitantes, en Arteterapia. Papeles de arteterapia y educación para inclusión social 13, 2018, 33-52.

\section{Introducción}

El presente artículo, que parte de la consideración de la educación patrimonial como fundamento de propuestas de trabajo inclusivas, surge en el seno de una investigación -en formato de tesis doctoral- vinculada al proyecto de I+D+I EDU2015/65716-C21-R financiado por el Ministerio de Economía, Industria y Competitividad y por los Fondos Feder.

En este trabajo se parte de la apreciación de la diferencia como valor añadido y del uso del término diversidad funcional para referirse a todas las personas, y no solo a las que tienen algún tipo de limitación, ya que todos, de una u otra forma, somos diversos.

Este documento trata de exponer cómo experiencias desarrolladas dentro y fuera de nuestras fronteras están mostrando que el trabajo en contextos educativos no formales, como los museos, no solo puede reducir nuestras limitaciones, sino también mejorar nuestras capacidades.

Cada vez son más abundantes las propuestas educativas que, en un intento de acercar la institución museística a las necesidades del visitante, proponen programas de educación patrimonial accesibles a diferentes colectivos poblacionales. Del encuentro con estas alternativas surge la necesidad de llevar a cabo una reflexión que analice las características de estos proyectos -con el fin de fijar las bases teóricas en las que se asientan-, sus principios de actuación, así como la adecuación de los mismos al público al que va dirigido, centro fundamental de toda acción educativa.

En este contexto, se plantea la identificación de las propuestas de educación patrimonial inclusivas que cuentan con elementos comunes que nos llevan a considerar que existen entornos patrimoniales potencialmente capacitantes, los museos.

\section{La diversidad como eje vertebrador de propuestas empoderadoras}

En ocasiones el empleo de determinadas aseveraciones resulta tan obvio que deja de reflexionarse sobre ellas. Una de estas obviedades es la afirmación «todos somos diferentes». Parece evidente que la diversidad, desde una consideración objetiva, es una característica intrínseca al ser humano. Todos somos diversos desde un punto de vista físico, algo que resulta indudable, pero también desde una perspectiva neuroanatómica. Esta afirmación no despierta ningún tipo de controversia puesto que los términos empleados para describir el hecho no contienen ninguna connotación negativa. El problema surge en el momento en que se asocia el término al de minusválido o discapacitado, en este caso, y por influencia de la consideración etimológica de la palabra (menos válido o menos capaz), la aseveración se convierte en peyorativa. No se considera que todos tenemos alguna no-capacidad, sino que se establece una categorización discriminatoria entre sujetos capaces y no capaces.

Millones de personas viven en todo el mundo con algún trastorno, síndrome o patología diagnosticada. Esta cifra, ya de por sí elevada, puede verse incrementada 
atendiendo a situaciones incapacitantes transitorias, sobrevenidas, adquiridas o degenerativas que, de manera directa o indirecta, todos podemos o vamos a tener que experimentar con el paso del tiempo.

Por tanto, y desde este punto de vista, todos somos o seremos discapacitados en algún momento de nuestra vida porque todos tenemos unas potencialidades y carecemos de otras. Sin embargo desde nuestra perspectiva, y dada la carga significativa que ha implicado históricamente este término, consideramos que es más adecuado emplear el concepto, propuesto en el año 2005 por el Foro de Vida Independiente, diversidad funcional, porque éste -en sí mismo- remite a una diferencia de funcionamiento real y socialmente más aceptada. Por este motivo hablaremos de diversidad funcional para referirnos a la caracterización de cualquier ser humano, y de clasificaciones concretas (según el trastorno o la patología) cuando una persona se encuentre diagnosticada de una determinada manera, entendiendo que estas categorizaciones son necesarias, no con el objetivo de discriminar a unos sujetos de otros, sino porque consideramos que del diagnóstico preciso de una patología depende su pronóstico. En la medida en que, salvando las diferencias personales, conocemos las características identificativas de un trastorno, podremos proponer una intervención más ajustada a sus necesidades, lo cual redundará en su beneficio.

La segunda de las «obviedades obvias» a las que nos queremos referir es el interés del ser humano por tomar sus propias decisiones y poder elegir sus opciones. Este hecho tan habitual en nuestras vidas pasa desapercibido al convertirse en una dinámica habitual, olvidando que no a todas las personas se les permite ejercerlo. El derecho de autodeterminación -entendido como la toma de consciencia de nuestro potencial- nos hace sentir parte de algo, nos ayuda a organizar y dirigir nuestra vida para crear el futuro que queremos, tanto individual como colectivamente. Nos empodera.

Al referirnos al término empoderamiento nos posicionamos en la línea de los estudios de Zimmerman (2000), que se refiere a este concepto como el proceso mediante el cual las personas llegan a ser capaces de tomar el control de sus circunstancias y de trabajar para mejorar su calidad de vida. Desde nuestra investigación defendemos la necesidad de empoderar a las personas con diversidad funcional para que, de acuerdo con sus posibilidades, puedan tomar sus propias decisiones y enfrentarse a situaciones que les permitan descubrir capacidades que, incluso ellas mismas, pueden desconocer. En este sentido, el planteamiento de la diversidad como elemento central en la consideración de toda propuesta empoderadora desarrollada en cualquier contexto, es la respuesta a las «obviedades obvias» a las que nos hemos venido refiriendo. Esta propuesta puede llevarse a cabo si, desde un principio, planteamos iniciativas inclusivas efectivas, que en el caso concreto de nuestra investigación se materializan en la creación de programas de educación patrimonial en espacios intrínsecamente inclusivos como son los museos.

\section{Los museos como contextos de inclusión social}

En los últimos años se han venido observando cambios paulatinos en la consideración de la diversidad desde diferentes ámbitos. El desarrollo de nuevas políticas educativas -denominadas inclusivas- que dejan de lado enfoques precedentes normalizadores o integradores, se ha centrado en el desarrollo de una atención educativa que 
favorezca al máximo las capacidades de los alumnos y que atienda a las necesidades de cada individuo de manera integral. Sin embargo, este hito - de enorme relevancia porque viene a constatar los cambios que se producen como fruto de las demandas sociales-, no siempre se ve materializado por no existir una conexión entre la teoría y la práctica. Contamos con programas inclusivos, en el mejor de los casos, en instituciones pretendidamente integradoras, que no están aún preparadas para atender a la diversidad de los públicos. Desde nuestra concepción, estas limitaciones vienen en ocasiones impuestas por la escasez de propuestas de trabajo que vinculen contextos formales y no formales, por la falta de trabajo cooperativo entre las diferentes instituciones y por el desconocimiento de la potencialidad de los museos como espacios educativos.

Consideramos que en la actualidad el museo se puede convertir en el espacio educativo inclusivo por excelencia, ya que contiene las condiciones necesarias para ser capacitante, accesible e inclusivo para todos los públicos. Su valor reside en su potencialidad para empoderar, para «(...) asumir una pedagogía de la inclusión en la que el sentimiento de pertenencia no se vincule a una identidad cultural determinada, sino que esté abierto a que una persona pueda tener múltiples pertenencias» (Massot, 2003, p. 179). Desde esta perspectiva, el museo se convierte en libertador ya que independiza y, simultáneamente, posibilita la elección propia. Esta conclusión llega como resultado de un proceso de transformación necesario, fruto de la comprensión de las circunstancias históricas y de las necesidades del momento, a través del cual se puede observar la variación de la concepción del museo como institución. De este modo, y como indica Fontal (2007) aludiendo a Olveira (2005), la transformación de las funciones de los museos ha variado desde la comprensión del espacio como receptor de objetos hasta la reubicación de la función del espectador y su posición esencial en el mundo de la creación. La misma autora apunta que en este proceso es el espectador, más incluso que el propio museo y sus contenidos, quien condiciona las transformaciones. La persona se convierte, por tanto, en el centro fundamental de propuestas educativas que tratan de ajustarse a sus necesidades e intereses, y que dan paso a planteamientos como los recogidos en el Plan Nacional de Educación y Patrimonio (Domingo, Fontal, Cirujano y Ballesteros, 2013) y en el Plan Museos+Sociales (SEC, 2015).

El valor de estas iniciativas reside en estimar la diferencia como un valor añadido, que renuncia al manido mito de Procusto, todavía hoy en día demasiado presente en nuestras instituciones educativas, y se apoya en la creación de espacios plenamente inclusivos como los museos. Desde esta concepción Rudy (2011) afirma:

En la escuela cada clase, test e interacción social depende sobre todo de las habilidades de las que carecen las personas con autismo. En cambio en un museo, conversación y comunicación social pueden a menudo mantenerse al margen para involucrarse en aprendizajes y descubrimientos visuales, auditivos o interactivos (p. 36).

En este contexto, el Plan Museos+Sociales, en un intento por adaptarse a las necesidades imperantes de la sociedad actual, reconoce el valor y la riqueza de la diversidad y propone alternativas para atenderla adecuadamente. De este modo propone las siguientes tipologías de museos: 
- Museo abierto: buscará atraer al público, mejorar su grado de satisfacción y ampliar el uso de sus recursos y servicios. Este museo es proactivo, irá al encuentro de sus públicos para abrirles sus puertas y construir conjuntamente actividades adaptadas a sus intereses.

- Museo accesible: es aquel que adapta sus instalaciones y contenidos a quienes tengan alguna discapacidad.

- Museo intercultural: es aquel que favorece una integración real y bidireccional de las comunidades inmigrantes a través del diálogo, el respeto mutuo, el conocimiento y la igualdad.

- Museo inclusivo: el que trabaja para que todos tengan su lugar. Sin excepciones. Planificará actividades adaptadas que potencien el autoconocimiento mediante la cultura.

- Museo sostenible: aquel que cuida el patrimonio y los recursos para las generaciones futuras.

Desde esta concepción, cada vez son más los museos que, en un intento por acercarse a las necesidades sociales imperantes, plantean programas comprensibles con el fin de acercar la institución a todo tipo de públicos, de hacer accesible el patrimonio.

Esto es posible gracias a que los museos, que asumen su papel como espacios innovadores, abiertos al diálogo y comprometidos, son -como indica el Plan Museos+Sociales- «garantía de una sociedad plural, cohesionada, crítica, libre y abierta» (SEC, 2015, p. 9). Son museos capaces de contribuir al desarrollo social, realizando para ello los cambios necesarios para que «la realidad pueda ser transformada y como instituciones autoconscientes de la necesidad de desempeñar una función social para cumplir su papel en la sociedad contemporánea» (SEC, 2015, p. 6).

Por tanto, hemos de aprovechar la función social de los museos para abrirlos a distintos públicos, dar visibilidad social y propiciar cambios en el entorno. Lo que en el Plan al que nos venimos refiriendo queda recogido del siguiente modo:

No se trata de renunciar a los principios de los museos tradicionales, sino de potenciar un museo adaptado a las nuevas necesidades de la sociedad, que hace frente a los retos que ésta plantea y es capaz de darles respuestas válidas y eficaces. Un museo entendido como una institución atenta, dinámica, reactiva, que apuesta por la creatividad, el diálogo y que se compromete con esa sociedad plural y diversificada a la que atiende (SEC, 2015, pp. 8-9).

Partiendo de las premisas hasta aquí expuestas proponemos la creación de un nuevo modelo que englobe todas las tipologías de museos expuestas para entender la institución de un modo integral, e incluso compensador. Nos estamos refiriendo al museo capacitante, que surge de la consideración de la educación patrimonial como disciplina capaz de crear entornos inclusivos y potencialmente capacitantes. 


\section{La educación patrimonial como disciplina inclusiva}

El arteterapia ha sido una de las disciplinas que mayor interés ha mostrado por trabajar con personas con diversidad funcional. Más concretamente, y centrándonos en el colectivo en el que focalizamos nuestra investigación -las personas con Trastorno del Espectro Autista (TEA)-, los primeros intentos de intervención con personas con TEA han estado marcados históricamente por el arteterapia. Numerosos estudios como los desarrollados por Prinzhorn (1922), Hill (1942) o Naumburg (1947), entre otros han servido de preludio a trabajos posteriores que, en un intento por acercarse al trastorno, han encontrado en esta disciplina la manera de implicar socialmente a colectivos discriminados.

Si bien es cierto que reconocemos el valor de esta labor, también lo es que debemos indicar que el objeto de nuestro estudio no se centra en la terapia, sino en la defensa de un modelo que, siendo intrínsecamente inclusivo, no precise de estrategias ajenas que faciliten la inserción efectiva de las personas en la sociedad. Concebimos que no tiene sentido incluir en un concepto algo que ya forma parte de él, es decir, no se debería de tener que pensar en incluir socialmente a grupos que ya forman parte de la sociedad. Lamentablemente el discurrir de los hechos muestra que esta incoherencia está presente, por lo que hemos de encontrar los medios necesarios para mostrar de qué manera se puede trabajar desde planteamientos inclusivos.

En este sentido, desde nuestra investigación, partimos de la concepción de la educación patrimonial como disciplina plenamente inclusiva porque desde ella se abordan las relaciones, no impuestas ni artificiales, que el sujeto establece con los bienes de modo consciente o inconsciente. Es en ese proceso, cuando la persona descubre el valor de un bien, cuando éste entra a formar parte de su repertorio vivencial y lo incorpora a su propio patrimonio a través de un proceso de personalización que le lleva a apropiarse (en sentido metafórico) de él, «(...) los elementos que nos emocionan comienzan a llamarse «nuestro patrimonio» porque es así como se sienten; se ha producido un primer vínculo de apropiación simbólica a través de la emoción» (Fontal y Valle, 2007, pp. 362-363). Gracias a esta primera conexión, el individuo es capaz de construir sus propios patrimonios simbólicos -lo que Fontal (2003) denomina vínculos-, o como indica Gómez Redondo (2013, p. 154) «generará una red de relaciones con el resto de patrimonios individuales». Esta red de relaciones puede ser mejor comprendida si pensamos en una cadena de eslabones construida a partir de elementos individuales, únicos, que contienen la posibilidad de permanecer aislados o de unirse con otros para crear una estructura conjunta. Cada uno de los eslabones posee un carácter identitario a nivel individual, pero también grupal, sin perder por ello su identidad. Del mismo modo sucede con el patrimonio, cada persona posee una serie de eslabones que pueden permanecer deslavazados o se pueden unir creando un constructo personal -su propio patrimonio individual-, pero también puede unir sus elementos a otros para generar un patrimonio colectivo. En ambos casos la importancia reside en el modo en que enlazamos cada pieza con las siguientes, es decir, en los vínculos que nos unen a otros patrimonios. Desde esta consideración, y tomando nuevamente como referencia a Gómez Redondo (2012, p. 19), «Es en este punto donde se hace patente la necesidad de la educación patrimonial como mediación entre individuo/s y patrimonio, visto como detonante de relaciones emocionales entre los sujetos del proceso». Estas 
relaciones generan un entramado en el que lo relevante son los vínculos que establecemos con el patrimonio, puesto que éstos se convierten en la herramienta que ensalza el valor del individuo de forma individual, pero también colectiva al hacerle formar parte de un conjunto social.

Por tanto, defendemos que la educación patrimonial es una disciplina inclusiva porque respeta y ensalza la importancia del individuo en su dimensión individual, pero también social. La educación patrimonial hace referencia a relaciones en las que lo relevante es la persona, sin connotaciones ni expectativas.

La relación existente entre los conceptos diversidad y educación patrimonial ha sido abordada por diferentes autores, entre los que destacamos a Marín (2014). Según la autora, la relación existente entre la inclusión y la educación patrimonial puede ser analizada desde diversas perspectivas. Concretamente se refiere a (Marín, 2014):

- La inclusión como contenido de la educación patrimonial. Desde esta perspectiva, y tal y como hemos indicado con anterioridad, se abordan las relaciones entre los bienes y las personas en el contexto en que se generan.

- La inclusión como metodología de la educación patrimonial. Se abordan los procesos de patrimonialización que, según la autora, se configuran como «método que guía los procesos horizontales de relación entre personas y bienes, generando nuevas relaciones» (Marín, 2014, p. 139).

- La inclusión como herramienta de la educación patrimonial. Desde esta concepción la inclusión sirve para construir patrimonios diversos desde el ensalce de la diversidad en contenidos como el patrimonio y la identidad.

- La inclusión como proceso de la educación patrimonial. Puesto que los procesos de patrimonialización serían en sí mismos inclusivos gracias a la incorporación y transformación de elementos a identidades preexistentes.

- La inclusión como contexto de la educación patrimonial. Desde esta concepción la diferencia es entendida como elemento vinculante porque el hecho de ser diversos es lo que nos une.

- La inclusión como finalidad de la educación patrimonial. Desde este enfoque la educación patrimonial se dirige a un modelo inclusivo ajustado a las necesidades sociales del momento.

Tal y como hemos mostrado, la educación patrimonial puede ser considerada como disciplina eminentemente inclusiva, puesto que contiene y genera diversidad de modo innato. Del mismo modo que el concepto persona lleva implícita la vida como característica esencial y, además, contiene la posibilidad de generar vida, es decir, es y contiene vida, la educación patrimonial es inclusiva y puede generar inclusión. 


\section{Entornos patrimoniales capacitantes}

El término entornos patrimoniales capacitantes, concepto creado en el seno de este estudio, embebe de diferentes disciplinas que, además de dar consistencia teórica a la propuesta (Vid. Figura 1), sirven de elemento vinculante y significativo para acciones educativas concretas.

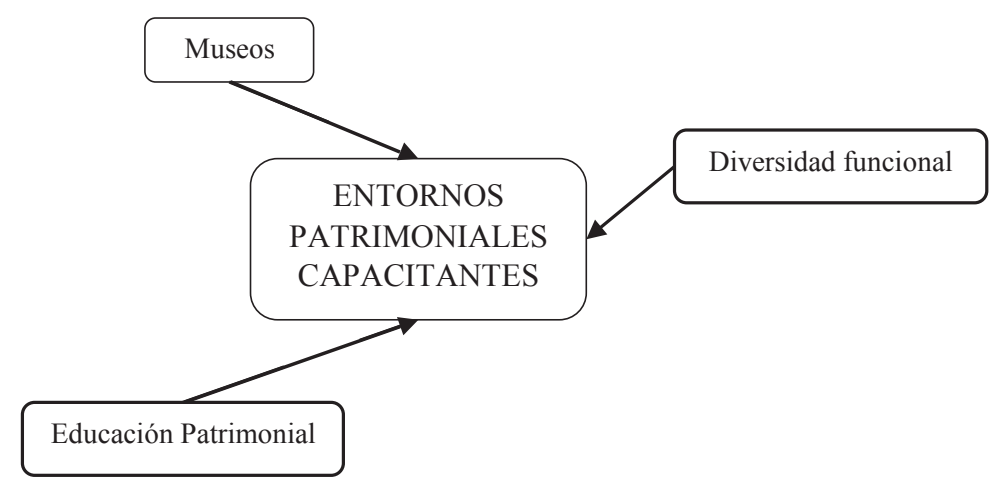

Figura 1. Fundamentación del concepto entornos patrimoniales capacitantes.

En un intento por ir más allá de la concepción de los museos inclusivos, planteada en el Plan Museos+Sociales y defendida por autores como Marín (2014), desarrollamos a continuación esta nueva conceptualización apoyándonos para ello en la relevancia, expuesta al inicio del presente artículo, que adquiere el concepto capacidad.

Defendemos que los museos, a través del trabajo en torno a propuestas de educación patrimonial, contienen las características necesarias para convertirse en capacitantes. Ello no supone que todos lo sean, serán las personas a través de sus acciones las que consigan que esta potencialidad se convierta, o no, en un hecho. En este sentido resulta interesante aludir a Roque Martins (2017), quien defiende la concepción de los museos (in)capacitantes a partir de la función de los mismos en la inclusión social de las personas con discapacidad. Aplicando este enfoque a nuestro trabajo valoramos el uso del término (in)capacitantes porque éste viene a resaltar la existencia de otros tipos de museos que probablemente también sean necesarios. Desde nuestro punto de vista lo relevante no es si el museo se define o no como capacitante, sino la potencialidad que alberga para llegar a convertirse en un entorno en el que la diferencia no sea identificada con la dificultad.

Del mismo modo que las personas somos diferentes, también han de existir diversos tipos de museos. La perspectiva que desde aquí planteamos no trata de homogenizar todas las instituciones para que cumplan un mismo papel. Creemos que cada museo tiene y ha de conservar su propia identidad porque es precisamente eso lo que le caracteriza y diferencia del resto. De esta reflexión cabe plantearse un interrogante lógico, ¿qué novedad aporta la creación del término museo capacitante? Desde una concepción como la nuestra, que defiende el carácter identitario de la institución, la respuesta nuevamente nos lleva al terreno de la potencialidad ya que entendemos 
que el museo se convierte en capacitante desde el momento en que el sujeto o grupo siente la necesidad de formar parte de algo, de generar un vínculo con el espacio, la colección, las personas... Desde ese momento la institución enlaza con los intereses, expectativas o anhelos de la persona y/o grupo y le otorga la posibilidad de crear su propio patrimonio en un acto libre, no impuesto, en el que lo realmente importante es la relación entre la persona y el bien.

El museo, entendido de esta manera, se transforma en un espacio en el que todos tenemos cabida porque en él las diferencias, lejos de ser disgregadoras, discriminatorias y discapacitantes, se convierten en positivas, aglutinadoras, únicas y enriquecedoras. Los visitantes dejan de ser meros espectadores, dejan de ser observadores externos que no establecen ningún vínculo con las muestras y las actuaciones que se diseñen, olvidan la tendencia de «programar para» y asumen la de «programar con» dejando a un lado el miedo a modificar tantas veces como sea necesario sus diseños.

Por tanto, podemos afirmar que el museo capacitante es aquel que cuenta con las siguientes características:

- No busca la inclusión porque es intrínsecamente inclusivo.

- Es aglutinador. Promueve la consideración de la diferencia como elemento enriquecedor, identitario y vinculante.

- Es empoderante, en él todas las personas pueden ejercer su derecho de autodeterminación.

- Sus diseños están concebidos desde la programación con todos los agentes, no para ellos.

- Toma la educación patrimonial como elemento transversal de todas sus propuestas.

- Es accesible en todas sus dimensiones.

- Fomenta el diálogo y la participación de y entre todas las personas.

- Está abierto a la mejora continua, para lo cual desarrolla redes cooperativas con otros agentes educativos.

- Mejora sus propuestas a través de la retroalimentación constante.

\section{Revisión de estudios en torno al TEA en museos}

Una vez establecidas las características del museo capacitante, y antes de proceder a exponer ejemplos concretos de propuestas que apoyan nuestra propuesta, consideramos necesario ofrecer una panorámica del origen y desarrollo de los estudios llevados a cabo con personas con TEA en el contexto museístico, ya que ello nos permitirá comprender de un modo más adecuado de dónde partimos y hacia dónde queremos llegar. 
En este sentido, resulta necesario hacer referencia a Bettelheim (1903-1990) quien, además de ser reconocido por su teoría de las madres nevera, destacó por estudiar la influencia en el arte de los arquetipos de Jung y la interpretación del arte como expresión del inconsciente freudiano (Artigas-Pallarés y Pérez, 2012, p. 576). Si bien es cierto que sus preceptos nada tienen que ver con la consideración que defendemos desde nuestro trabajo, también lo es que se puede erigir como precursor en el estudio de las relaciones entre el autismo y las manifestaciones artísticas.

En los años cuarenta Hans Asperger (citado en Arsic, 2017) indicó que para triunfar en la ciencia y en el arte es esencial un toque de autismo. A este respecto, aunque no hay evidencias científicas que lo avalen, grandes mentes de la historia han sido «consideradas» como autistas. De hecho, aún hoy en día encontramos estudios que asocian las altas capacidades con un tipo específico de autismo -los denominados «savant»- que han destacado en alguna disciplina artística, bien por su talento musical o por su capacidad para expresar por medio del dibujo, la pintura o la escultura. Sin embargo, y puesto que éstos representan una parte del conjunto de población con TEA consideramos que no debemos circunscribir nuestra revisión a este grupo minoritario, sino referirnos a todos aquellos que se encuentran dentro del espectro.

Tradicionalmente, al hablar del autismo relacionándolo con manifestaciones expresivas, se ha recurrido a emplear el arte como terapia, es decir como una forma de psicoterapia que emplea las artes plásticas como medio para rehabilitar. Los antecedentes del arteterapia en personas autistas se reducen a experiencias aisladas llevadas a cabo en diferentes lugares del mundo. Concretamente en Inglaterra hace veinte años se defendió la primera tesis que abordaba específicamente ambos términos titulada: Art therapy and de development of communicative abilities in children with autism.

Estudios posteriores, como el de Fernández Añino (2003) desarrollado a partir de los estudios de Paul Harris -Psicólogo de la Universidad de Oxford-, defienden que las personas con autismo, al presentar dificultades en cuanto al juego de ficción espontáneo, de juego simbólico espontáneo o de juego de roles, tendrían dificultades para ser creativos, ya que carecerían de la capacidad de imaginar o de interpretar el mundo exterior. Además, añade que se puede hablar de arte en personas con este trastorno, pero siendo éste un arte caracterizado en algunos casos por la falta de ficción, falta de capacidad para imaginar realidades alternativas. También recuerda que durante mucho tiempo la creatividad fue identificada con la inteligencia hasta el punto de creer que las personas con un cociente intelectual bajo eran incapaces de desarrollarse creativamente (Fernández Añino, 2003).

Estas conclusiones, unidas a las de diferentes estudios realizados sobre personas con TEA, vendrían a apoyar que las personas autistas no son personas creativas. Sin embargo, diferentes propuestas llevadas a cabo con personas con discapacidades físicas, mentales o de desarrollo (véase como ejemplo el Creative Growth Art Center) han mostrado que se puede ofrecer una experiencia constructiva sobre cómo pasar del déficit hasta la actividad y la participación social. Éste es un buen ejemplo del modo en que las resiliencias pueden generar cambios importantes, lo que dicho en palabras de uno de sus fundadores, Katz (1977), vendría a resaltar que todo el mundo, independientemente de lo severas que sean sus discapacidades, tiene un potencial creativo. 
Por tanto, parece claro que la asociación inteligencia-creatividad no va siempre unida, y que la experiencia artística puede conllevar innumerables beneficios independientemente de las capacidades que el sujeto tenga (Parada Carmelo, 2012).

En la actualidad, si bien no encontramos en nuestro país estudios rigurosos que establezcan de qué manera se puede abordar el trabajo específico con personas con espectro autista en museos; sin embargo, sí que proliferan los posgrados de especialización ofrecidos en torno al tema arteterapia con colectivos concretos y proyectos de trabajo que, en la búsqueda de espacios educativos inclusivos, encuentran aquí una herramienta útil con gran valor terapéutico. Ya que, como expone Herbert Read (1982) «No se trata de dar clases de arte. Lo que interesa es desarrollar las capacidades artísticas: belleza, expresión, creatividad, para promover el desarrollo personal. Imaginar, fantasear, divagar, soñar, invitar, crear, recrear es esencial al proceso educativo» (citado en Hope Canto, 2009, p.18).

\section{La teoría puesta en práctica: ejemplos referentes}

Una vez expuesto el estado del arte en torno a nuestro objeto de investigación y centrada nuestra plausible propuesta teórica, pretendemos mostrar -mediante la exposición de un referente concreto- que los museos capacitantes pueden convertirse en un hecho porque cuentan con el contexto educativo y las condiciones sociales adecuadas para ello. Prueba de esto es que en la actualidad ya existen programas desarrollados en museos que, sin saberlo, son ejemplos reales que materializan esta concepción. Tal es el caso del Museo ICO, un espacio que en su intento por convertirse en un entorno abierto para todo tipo de colectivos, ha desarrollado la propuesta Empower Parents, una iniciativa educativa dirigida a personas con TEA, sus familias y los agentes que trabajan tanto en el museo como en las asociaciones de personas con TEA.

El programa Empower Parents fue puesto en marcha en 2013 entre el Queens Museum de Nueva York, la Fundación ICO y la plataforma Hablaenarte con el fin de «compartir recursos y generar un mayor impacto de las acciones realizadas en materia de inclusión social en ámbitos museísticos culturales». Esta iniciativa centrada en el trabajo con el colectivo de personas con TEA, sus familias, las administraciones locales, entidades y colectivos profesionales, es novedosa en nuestro país, pero en otros como Estados Unidos cuenta con una amplia y variada tradición. En esta línea de trabajo encontramos ejemplos de programas basados en los principios que acabamos de describir. Tal es el caso del Portland Children's Museum, a través del programa Access Play at the Museum, el Explore and More Children's Museum con su proyecto Au-Some Evenings, el Queens Museum of Art de Nueva York, el Children Discovery Museum de San José a través del programa Play your Way o el Guggenheim Museum con el proyecto Guggenheim for All entre otros.

Desde nuestra concepción el programa Empower Parents es un buen ejemplo de propuesta capacitante porque trabaja desde una perspectiva multidisciplinar en la que cada agente colaborador en el proceso cuenta y es importante para crear un producto accesible y ajustado a las necesidades de los participantes. No solo no se desdeña la colaboración de los mejores conocedores de las personas con TEA, sus 
familias y redes de apoyo, sino que se les empodera para que puedan formar parte de un proceso que les implica directamente al ser la referencia más cercana para la persona con TEA. A menudo, en los contextos educativos, se programan diseños que, a pesar de ser buenos ejemplos teóricos de lo que se podría hacer, resultan inútiles por no ajustarse a las características y necesidades de las personas. En su proceso de programación olvidan el objetivo primordial del mismo o desarrollan una imagen «idílica» del sujeto que poco tiene que ver con sus capacidades. Y es precisamente en este punto donde esta iniciativa entronca con nuestra propuesta, en el valor que adquiere al empoderar las capacidades de un entorno que, siento de por sí ya inclusivo, da un paso más allá mostrando la necesidad de contar con los conocimientos y saber hacer de los participantes y visibilizando capacidades que, aun siendo intrínsecas a ellos, desconocen.

El éxito de estos planteamientos, tal y como se indica desde la propuesta de Empower Parents, radica en contar con dos aspectos fundamentales interrelacionados. El primero de ellos es que surge de una necesidad social real y relatada por sus protagonistas y el segundo que cuenta con un importante trabajo de investigación en constante proceso de evaluación formativa para ajustarse a las necesidades de sus participantes. Estos hechos son los que convierten a la propuesta en capacitante, y los que han suscitado que esta iniciativa, actualmente de carácter mundial, haya sido extrapolada a otras instituciones como el Museo Thyssen-Bornemisza, el Museo de la Ciencia de Valladolid, el Espacio Fundación Telefónica, el Museo del Traje-CIPE o el Medialab Prado.

Además, y vinculando este planteamiento a nuestra investigación de modo concreto, consideramos que éste puede ser una buena muestra de lo que consideramos que ha de entenderse como institución capacitante, ya que cuenta con los criterios que -desde nuestro estudio- hemos establecido como básicos para poder trabajar desde una perspectiva inclusiva. Éstos son:

- El programa muestra el conocimiento del colectivo con el que se trabaja.

- Las propuestas consideran los grados de severidad del trastorno y plantean diseños ajustados a las necesidades de cada persona.

- Se plantea la adecuación de los recursos, espacios y soportes, así como el ajuste al contexto social, cultural y/o educativo.

- Los diseños se ajustan al grado de competencia cognitiva, curricular y/o social de los usuarios.

- Se fomenta la coordinación e implicación de agentes educativos en los proyectos, lo que asegura la visión multidisciplinar necesaria en este tipo de diseños.

- La iniciativa es difundida con el objeto de dar visibilidad a su trabajo, y a los resultados de ellas obtenidos.

Por tanto, podemos afirmar que - a la luz de los datos obtenidos desde nuestro estudio- los museos capacitantes pueden convertirse en una realidad en la que la democratización del espacio sea realmente efectiva. 


\section{Conclusiones}

Retomamos el inicio de este artículo para destacar cómo la investigación desarrollada ha servido de base para el estudio, no solo del concepto aquí abordado, sino de propuestas de trabajo desarrolladas dentro y fuera de nuestras fronteras. Con ello hemos podido constatar que el término inclusión está cada vez más presente en el ámbito educativo, aunque desgraciadamente más desde un planteamiento teórico e institucional que práctico y efectivo. Sin embargo, es preciso indicar que la proliferación de diseños de trabajo inclusivos en entornos educativos no formales está propiciando un cambio de perspectiva al mostrar que otras prácticas son posibles. Parte de estas propuestas pueden ser estimadas como capacitantes desde el momento en que consideran el espacio como lugar de encuentro, de intercambio de experiencias -individuales y colectivas- que conecta con nuestros intereses, nos sensibiliza y predispone a disfrutar aprendiendo.

A través de este trabajo se ha evidenciado que este tipo de planteamientos comienzan a tomar peso en nuestro país, fruto del interés de las personas por mejorar las prácticas existentes. No podemos olvidar que, tal y como hemos venido exponiendo, nuestra perspectiva sitúa en el centro de toda acción a las personas, y es precisamente gracias al interés y trabajo de esas mismas personas por lo que iniciativas de este tipo están mostrando que los entornos patrimoniales inclusivos no pueden ni deben quedarse en el plano teórico.

\section{Referencias bibliográficas}

Arsic, J. (10 de mayo de 2017). Entrevista a Daniel Tammet. Jot Down Cultural Magazine. Recuperado de http://www.jotdown.es/2017/05/daniel-tammet-autismo-ha-contribuidogran-medida-las-ciencias-arte/

Artigas-Pallarés, J. y Pérez, I. P. (2012). El autismo 70 años después de Leo Kanner y Hans Asperger. Revista de la Asociación Española de Neuropsiquiatría, 32 (115), 567-587.

Domingo, M.; Fontal, O.; Cirujano, C. y Ballesteros, P. (Coords.) (2013). Plan Nacional de Educación y Patrimonio. Madrid: Ministerio de Educación, Cultura y Deporte.

Fernández Añino, M. I. (2003). Creatividad, arte terapia y autismo. Un acercamiento a la actividad Plástica como proceso creativo en niños autistas. Arte, individuo y sociedad, 15, 135-152. Recuperado de https://revistas.ucm.es/index.php/ARIS/article/viewFile/ ARIS0303110135A/5837

Fontal, O. (2003). La Educación Patrimonial: teoría y práctica para el aula, el museo e internet. Gijón: Trea.

Fontal, O. (2007). ¿Se están generando nuevas identidades? Del museo contenedor al museo patrimonial. En R. Calaf, O. Fontal, y R.E. Valle (Eds.), Museos de arte y educación: construir patrimonios desde la diversidad (pp.27-52). Gijón: Trea.

Fontal, O y Valle, R. E. (2007). Del museo al aula: disfrutar desde la diversidad. En R. Calaf, O. Fontal, y R.E. Valle (Eds.), Museos de arte y educación: construir patrimonios desde la diversidad (pp.361-386). Gijón: Trea.

Gómez Redondo, C. (2012). Patrimonio e identidad: La educación patrimonial como vínculo entre individuo y entorno. En O. Fontal, P. Ballesteros y M. Domingo (Coords.), I Congreso Internacional de Educación Patrimonial. Mirando a Europa: estado de la cuestión y perspectivas de futuro (pp. 15-22). Madrid: Instituto del Patrimonio Cultural de España-Observatorio de Educación Patrimonial en España. 
Gómez Redondo, C. (2013). Procesos de patrimonialización en el arte contemporáneo: diseño de un artefacto educativo para la identización. (Tesis doctoral). Recuperada de https://uvadoc.uva.es/bitstream/10324/3568/1/TESIS350-130920.pdf

Hoppe Canto, M. (2009). Pedagogía desde el Arte. Manual de introducción. México DF: Save the children México.

Marín Cepeda, S. (2014). Educación patrimonial y diversidad: evaluación de programas y definición de un modelo basado en los proyectos de patrimonialización (Tesis doctoral). Recuperada de http://uvadoc.uva.es/bitstream/10324/7416/1/TESIS601-141204.pdf

Massot, M. I. (2003). Jóvenes entre culturas: La construcción de la identidad en contextos multiculturales. Bilbao: Desclée De Brouwer.

Parada Carmelo, A. J. (2012). El Síndrome de Asperger y la creatividad. El desarrollo de las habilidades sociales a través del arte-terapia (Memoria de máster). Recuperado de http://digibuo.uniovi.es/dspace/bitstream/10651/3990/1/TFM_AlejandroJacob_Parada_ Camelo.pdf

Roque Martíns, P. (2017). Museos (In)Capacitantes, Deficiencia, Accesibilidad e Inclusión en Museos de Arte. Casal de Cambra: Caleidoscopio.

Rudy, L. J. (2011). Full Spectrum. Addressing the Needs of Kids with Autism. Recuperado de: http://www.aam-us.org/docs/default-source/museum/full-spectrum-addressing-theneeds-of-kids-with-autism.pdf?sfvrsn $=0$

Secretaría de Estado de Cultura de España (2015). Plan Museos+Sociales. Recuperado de: http://www.mecd.gob.es/dms/microsites/cultura/museos/museosmassociales/presentacion/ plan-museos-soc.pdf

Zimmerman, M. A. (2000). Empowerment theory: Psychological, organizational, and community levels of analysis. En J, Rappaport y E. Seidman (Eds.), Handbook of community psychology (pp. 43-63). New York: Plenum. 